\title{
ВЫЗОВЫ СОВРЕМЕННОГО ФИЛОЛОГИЧЕСКОГО ОБРАЗОВАНИЯ В УСЛОВИЯХ СОЦИАЛЬНОЙ ИНТЕГРАЦИИ
}

\section{CHALLENGES OF MODERN PHILOLOGICAL EDUCATION IN THE CONTEXT OF SOCIAL INTEGRATION}

M. Ivanova

Summary: To summarize the currently available information on sociopsychological adaptation in the context of globalization; identify the main categories of difficulties faced by foreign students studying at Russian universities; to define the role of philological education in the process of solving the indicated problems.

Analysis of general data on the impact of globalization on the world educational space; analysis of factors that positively and negatively affect the processes of integration and adaptation of students in a new environment; analysis and generalization of pedagogical experience; analysis and classification of the main methods of solving the assigned pedagogical problems.

The methodological base and tools of Russian universities require adjustment due to problems associated with the socio-cultural characteristics of foreign students and poor command of the language of the host country.

The study of the problems of foreign students currently studying in higher educational institutions makes it possible to determine the influence of constantly changing external conditions under the influence of globalization on the adaptation of students to the educational process in a potentially new environment for them, and the data obtained will help to maintain the social, educational and linguistic environment of the university in the future.

Keywords: globalization, adaptation, integration, philology, teaching, foreign students.

\author{
Иванова Мария Михайловна \\ Преподаватель, Финансовый университет при \\ Правительстве Российской Федерации \\ MMlvanova@fa.ru
}

Аннотация: 0бобщить имеющиеся на данный момент сведения о социально-психологической адаптации в условиях глобализации; выявить основные категории трудностей, с которыми стакиваются иностранные студенты, обучающиеся в российских вузах; обозначить роль филологического образования в процессе решения обозначенных проблем.

Анализ общих данных о влиянии глобализации на мировое образовательное пространство; анализ факторов, положительно и отрицательно влияющих на процессы интеграции и адаптации студентов в новой среде; анализ и обобщение педагогического опыта; анализ и классификация основных приемов решения поставленных педагогических задач.

Методологическая база и инструментарий российских вузов требуют корректировки ввиду проблем, связанных с социокультурными особенностями иностранных студентов и слабым владением языком принимающей страны. Изучение проблем иностранных студентов, обучающихся в настоящее время в высших учебных заведениях, позволяет определить влияние постоянно меняющихся внешних условий под воздействием глобализации на адаптацию студентов к образовательному процессу в потенциально новой для них среде, а полученные данные помогут выстаивать социально-воспитательную и языковую среду университета в будущем.

Ключевые слова: глобализация, адаптация, интеграция, филология, обучение, иностранные студенты.

глобализации образуется качественно новое состояние мира, приходящее на смену старому.

Кроме того, акцентируя внимание на человеке как первостепенном субъекте глобализации, можно сказать, что глобализация - это поэтапный процесс познания людьми как друг друга, так и окружающего их пространства, а также установление устойчивых связей, в результате чего образуется целостная социальная структура, отличающаяся взаимосвязанностью и взаимозависимостью входящих в нее компонентов по всем ключевым параметрам.

Отсюда следует, что глобализация представляет собой достаточно закономерный системный процесс 
полномасштабной интеграции всех социальных составляющих мира и параллельно происходящую унификацию сфер общественной жизни в пределах различных сообществ и социальных институтов.

\section{Материалы и методы}

Принимая во внимание все преимущества и нововведения, основы которым были заложены непосредственно в ходе глобализации, стоит помнить и о ряде проблем, вызванных последствиями неизменно сопровождающих глобализацию процессов. Так как экономические, социальные, культурно-духовные перспективы глобализационного процесса не вызывают сомнений, благодаря его детальному изучению на всех уровнях жизни появилась возможность корректировать многие конфликтные аспекты. Основным фактором интеграционного процесса является именно стабильность и гармония экономики государств. Современные государства очень тесно взаимодействуют друг с другом, что, с одной стороны, способствует успешной и быстрой интеграции политических пространств, но, с другой Уприводит к потере своей идентичности, традиций и устоев, что является губительным для любой нации.

Однако если говорить о понятии глобализма и глобализации, следует отметить, что важнейшей составной частью глобализации стала так называемая языковая глобализация - процесс активного взаимопроникновения языков в условиях доминирования одного из языков в качестве мирового. Как известно, термин «языковая глобализация» имеет два значения: использование английского языка в качестве средства научных и политических контактов; американизация национальных языков [11]. Таким образом, многие исследователи задались вопросом, каким должен быть этот универсальный глобализованный язык и какие критерии предъявлять к уже существующим языковым системам. Интернационализация экономики, масштабная миграция населения и социальные процессы обусловили формирование социального заказа, требующего от языка быть понятным и доступным всем его носителям. В результате многие филологи пришли к выводу, что глобализация языка - это неизбежность, обусловленная глобализацией общества, и необходимость, обеспечивающая языку жизнеспособность и выживаемость в условиях жёсткой конкуренции [7].

Говоря о социальной интеграции, остро встает вопрос о формировании определенной среды, в которой мигранты могли бы чувствовать себя комфортно в иноязычном обществе, адаптировались к новым условиям и были способны найти свою нишу с минимальными последствиями для себя и окружающих. Одной из причин современной миграции является желание получить высшее профессиональное образование, специализа- цию в конкретной области знаний или повышение уже имеющейся квалификации в выбранной сфере деятельности. На данном этапе перед филологической наукой встает ряд определенных трудностей, включая интернационализацию образования и инновацию действующих образовательных программ ведущих вузов стран, вовлеченных в международную деятельность. Кроме того, возрастает необходимость решения проблем, связанных с адаптацией иностранных студентов в новой межкультурной образовательной среде. И речь идет не только о проблемах, обусловленных отсутствием элементарных навыков говорения на языке принимающей страны, но и о культурных особенностях, субординации и так далее. Для оптимизации всех описанных выше процессов и успешной полноценной интеграции студентов необходимо учитывать и индивидуальные особенности их адаптированности [9]. Однако данный аспект недостаточно изучен в современных исследованиях, из чего следует, что, в первую очередь, необходимо изучение проблем межкультурной адаптации и разработка конкретных предложений для ее реализации.

В контексте образовательной среды Российской Федерации и, в частности, высшей школы, одной из важнейших актуальных задач на сегодняшний день является интеграция российской системы образования в мировое образовательное пространство, учитывая накопленный отечественный опыт и традиции государства. Многие филологи и лингводидакты озабочены тем, что в стране отсутствует единое образовательное пространство, в федеральных образовательных стандартах нового поколения отсутствует конкретика, необходимая преподавателю. Для повышения конкурентоспособности российских вузов среди ведущих мировых научно-образовательных центров, а также выпускаемых ими специалистов необходим детальный пересмотр первопричин возникающих проблем и поиск их решений в кратчайшие сроки. Основной целью, стоящей перед правительством на текущий момент, является построение принципиально нового уровня российского образования, отвечающего социальным нуждам в эпоху глобализации и постиндустриализации с учетом накопленного опыта.

В последние годы российские вузы активно подключились к борьбе за иностранных студентов, что находит свое отражение в ежегодном мониторинге эффективности вузов. На протяжении последнего десятилетия региональные вузы должны были привлекать к обучению не менее 0,7 процента, тогда как вузы Москвы и Санкт Петербурга - не менее 3 процентов иностранных студентов от общего контингента [4, с. 92]. Таким образом, основной целью программы по рекрутингу иностранных студентов является интеграция вузов в международное научно-образовательное пространство, а также активное привлечение в Россию ведущих зарубежных ученых и специалистов. В числе иностранных студентов широко 
приветствуются потенциальные учащиеся из ближнего и дальнего зарубежья, что в свою очередь влечет за собой тотальную реорганизацию международных служб и повышение квалификации сотрудников в большинстве российских вузов.

Как правило, начало обучения в вузе характеризуется первичной адаптацией к новой образовательной среде, а значит, этот период можно назвать одним из наиболее сложных этапов обучения для всех студентов, особенно для иностранных. Все более усиливающаяся интернационализация современного высшего образования делает проблему адаптации иностранных студентов к обучению в вузе незнакомой страны актуальной и приоритетной. Другими словами, академическая мобильность молодых людей, желающих получать образование за рубежом, неизменно будет сопровождаться совершенно новыми условиями жизни, ростом эмоциональных и информационных нагрузок, а также необходимостью социализироваться. Ввиду того, что нынешняя ситуация на рынке высшего образования предъявляет новые требования к качеству обучения иностранных студентов, необходимо учитывать способности студентов к адаптации для их успешной интеграции в новую среду, оптимизируя данный процесс. Помимо этого, перед образовательными учреждениями так же стоит проблема решения материально-технических и педагогических задач, а это может потребовать создания качественно новых направлений образования в целом и филологии в частности.

Социальная адаптация, будучи сложным и многоуровневым процессом, означает приспособление личности или социальной группы, попавшей в нехарактерную жизненную ситуацию, к реальной социальной среде. Описанный процесс начинается с осознания личностью того обстоятельства, что ее прежнее поведение не содействует достижению успеха и необходимо менять модель поведения с учетом требований новой социальной среды. С учетом вышесказанного можно дать определение понятия «социально-психологическая адаптация».

Согласно А.А. Налчаджян под ней понимается личностная адаптация, то есть адаптация личности к социальным проблемным ситуациям, привыкание индивида к новым условиям внешней среды с затратой определенных сил, взаимное приспособление индивида и среды. Результатом процесса адаптации становится адаптированность как наиболее устойчивое состояние организма в новых условиях [6].

Для успешного завершения процесса адаптации необходимы двусторонние изменения во взаимодействующих объектах. Иначе говоря, решающими условиями достижения положительного результата являются такие условия как активность, контактность и двусторонние изменения. Наличие всех трёх условий определяет наи- более приемлемую стратегию адаптации, следуя которой индивид устанавливает контакт с конфликтной средой и способствует изменению как среды, так и себя, выстраивая систему взаимодействия.

Таким образом, можно выделить такие цели социально-психологической адаптации как самореализация, развитие способностей для успешного осуществления поставленных целей, в том числе образовательных, превращение в самодостаточную социальную личность для продолжения профессиональной деятельности в выбранной сфере в любой социокультурной среде. Кроме того, некоторые специалисты, включая кандидата психологических наук С.И. Розума, полагают, что целью социализации и социальной адаптации следует считать «создание субъектом в процессе его общения и совместной деятельности такой субъективной картины мира, которая бы в значительной мере соответствовала бы картине, разделяемой большинством членов сообщества. Только при данном условии субъект может адекватно действовать в социальной среде и реализовывать свои цели и задачи» [8, с. 244].

С момента поступления в российские вузы иностранные студенты начинают испытывать ряд трудностей, основной причиной возникновения которых, безусловно, является недостаточное владение русским языком. Как правило, иностранные студенты достигают определенных успехов в овладении языком, обретают достаточный словарный запас и начинают активно использовать свои новоприобретенные знания лишь к третьему курсу. Кроме того, в новых обстоятельствах студенты сталкиваются с проблемой индивидуальной работы, так как у них полностью или частично отсутствует навык конспектирования, работы с источниками информации и анализа данных большого объема. Различные виды практической и проектной деятельности, подразумевающей взаимодействие с другими учащимися в парах и в небольших группах, так же вызывает стресс ввиду непривычности и неумения правильно организовать работу. Как следствие, у студентов наблюдается перегрузка учебными материалами и накопление неосвоенного материала, что неминуемо ведет к неуспеваемости по изучаемым предметам.

Успешное обучение иностранных студентов в российских высших учебных заведениях определяется не только их готовностью к тем методам и приемам обучения, которые приняты в конкретных вузах, но и в готовности образовательных учреждений приспосабливаться к их нуждам с учетом их социокультурных особенностей.

Принимая во внимание все вышесказанное следует выделить роль филологического образования в процессе адаптации иностранных студентов, а также определить ряд проблем, с которыми сталкивается научно-пе- 
дагогический состав в ходе подготовки курса обучения профильным предметам и иностранным языкам. В связи с разнородностью национального состава учебных групп и различными уровнями знания русского языка важно обеспечить соответствующие условия социализации иностранных студентов не только во время занятий, но и в самостоятельной работе.

Разнообразие факторов, влияющих на процесс адаптации иностранных студентов, и подходов к их интерпретации объясняется фактической разницей в социокультурной обстановке различных стран и регионов России. Основная текущая задача - выявить и описать круг проблем, с которыми приходится иметь дело иностранным студентам, и определить их влияние на адаптацию студентов к образовательному процессу вуза. Адаптационные трудности возникают на различных уровнях: языковом, понятийном, нравственно-информационном, бытовом, коммуникативном и так далее. Исходя из этого, выделают следующие категории:

- психофизиологические трудности, подразумевающие первоначальную перестройку личности и первые шаги на пути вступления в новую культурную и образовательную среду;

- учебно-познавательные трудности, связанные с преодолением языкового барьера и различий в системах образования, включающих новые требования и систему контроля знаний, организацию учебного процесса и привития навыков самостоятельной работы, строящихся на принципах саморазвития личности;

- коммуникативные трудности, в том числе с преподавателями и сотрудниками университета, а также в процессе межличностного общения внутри учебной группы, учебного потока, в общежитии и так далее;

- бытовые трудности, связанные с отсутствием навыков самостоятельности.

Следовательно, иностранные студенты чаще всего акцентируют внимание на проблемах с:

- языковой средой;

- культурной средой, то есть менталитетом;

- межличностной средой и нормами общения;

- иными традициями обучения;

- бытовым самообслуживанием;

- удаленностью от родных и близких [5, с.230-231].

И.А. Поздняков обращает внимание на ряд специфических педагогических проблем, возникающих у иностранных студентов, включающихся в образовательный процесс российского вуза:

- проблемы выбора образовательно-профессионального маршрута;

- проблемы овладения знаниями и навыками основной деятельности;
- проблемы межличностного взаимодействия и взаимодействия с окружающей социальной средой;

- проблемы безопасности жизнедеятельности;

- проблемы организации досуга и овладения дополнительными знаниями и навыками [2].

Отсюда следует, что филологический аспект выходит на первый план, так как необходимое для скорейшей адаптации обобщение опыта работы вузов и поиск новых форм и методов учебно-воспитательной работы с иностранными учащимися невозможен без определенного уровня языковой подготовки как студентов, так и преподавателей.

Рассмотрим основные методы решения данных проблем и повышения результативности учебной деятельности:

\section{1. Организашия языковых курсов А^я студентов}

Многие студенты, недостаточно свободно владея русским языком, не способны отсеивать второстепенную информацию и тезисно конспектировать основные понятия. Для освоения этого навыка иностранному студенту необходимо иметь достаточно высокий уровень владения неродным языком. Внутривузовские языковые курсы помогут учащимся приобрести базовые знания языка и коммуникативные навыки для скорейшей социализации. Кроме того, в процессе изучения русского языка как иностранного на семинарских занятиях студенты имеют на руках тексты, адаптированные по специальности, что позволяет им сопоставлять услышанное на лекциях с увиденным в учебнике, что положительно сказывается на усвоении материала. Благодаря подобным курсам студенты более уверенно чувствуют себя на занятиях и в бытовых жизненных ситуациях, снижается психологический дискомфорт и создается положительная динамика в дальнейшей адаптации иностранцев к российской действительности.

\section{2. ААаптация учебных пособий}

Дополнительную трудность представляет собой работа с учебными пособиями. Иностранные учащиеся пользуются теми же учебными материалами, что и студенты-россияне. Большинство учебников написаны хрестоматийным языком, что зачастую вызывает трудности и у носителей русского языка. Для решения проблемы понимания материала по общенаучным дисциплинам необходимо создание преподавателями-предметниками отдельных учебных пособий для иностранных учащихся. При этом во избежание чрезмерной терминологической перегруженности рекомендуется тесное сотрудничество и консультирование с преподавателями русского языка как иностранного. Для наиболее эффек- 
тивного формирования предметных знаний авторам пособий следует ориентироваться на следующие факторы:

- уровень владения русским языком иностранных учащихся;

- конкретная тематика и задания, направленные непосредственно на самостоятельную работу студентов;

- единая структура упражнений до и после основных текстов каждого раздела;

- элементы наглядности и визуализация введенных терминов;

- словарь профессиональных терминов, фигурирующих в разделах учебника.

\section{3. ААаптация учебных мохелей}

Большинство форм проведения занятий являются новыми для иностранных учащихся. Для разработки методики успешного обучения иностранного контингента необходимо в первую очередь учитывать все его особенности. Построение образовательного процесса невозможно без учета использования этнопедагогических концепций, методик и технологий. Как известно, на систему образования влияют географические, экономические, национальные, исторические, культурные и религиозные факторы, причем со своей спецификой у каждой отдельной нации. Каждый народ имеет свои подходы, применяемые в педагогическом процессе, которые необходимо принимать во внимание в процессе обучения иностранных студентов. Для наиболее эффективного включения студента в новую среду необходимо:

- создавать языковые ситуации, максимально приближенные к реальности;

- поднимать вопросы, актуальные для конкретной студенческой аудитории;

- учитывать возрастную, религиозную, социальную принадлежность студента;

- поощрять инициативу иностранных студентов;

- объективно оценивать результаты их самостоятельной деятельности;

- формировать интерес и стимулировать познавательную потребность у иностранного студента.

\section{4. Разделение на моно- и многонациональные группы}

В отличие от мононациональных групп многонациональные подразумевают совместное обучение представителей различных культур. Доказано, что иностранные студенты гораздо увереннее чувствуют себя в группе, где учатся только их соотечественники. Это может быть связано с тем, что в мононациональной группе сплочение коллектива происходит гораздо быстрее, так как базируется на общих традициях, обычаях и нравах, формируя определенную линию поведения. Схожее мировосприятие и нормы поведения личности служат своеобразным регулятором отношений в университете, поддерживают дисциплину и помогают наладить и упорядочить учебный процесс. Однако преподавание в многонациональных группах, несомненно, имеет свои преимущества. Очевидно, что успешное приспособление иностранного студента к новой среде происходит благодаря активному взаимодействию с русскоговорящими студентами. Благодаря налаживанию дружеских отношений их кругозор расширяется, а социально-психологическое состояние стабилизируется.

\section{5. ИнАИви уальный по $х х о \Delta$}

Наилучшим сценарием для вовлечения иностранного учащегося в учебный процесс является интеграция, при которой происходит активное освоение иной национальной культуры при сохранении собственной национальной идентичности. Именно интеграция в новое культурное окружение становится главным показателем успешной адаптации. Так одной из важнейших задач педагога становится приобщение иностранных студентов к русским национально-культурным традициям посредством внеучебной деятельности. Насыщенная общественная жизнь в студенческой среде и активное участие в общих институтских мероприятиях, включая подготовку к различным конференциям, фестивалям или спортивным соревнованиям также оказывают положительное влияние на деловую и эмоциональную включенность иностранных студентов. Проблема налаживания дружественных контактов среди студентов не должна игнорироваться профессорско-преподавательским составом любого учебного заведения. С целью формирования коммуникативных умений иностранных студентов преподаватели могут организовывать и проводить круглые столы для обсуждения материала в рамках пройденной тематики, разбор ситуативных заданий по осваиваемому профилю, а также проведение дебатов, в том числе двуязычных. Формирование подобных навыков может быть более успешным, если процесс обучения будет осуществляться с учетом национальных и этнокультурных особенностей.

\section{6. Повышение квалификашии преподавателей и развитие языковых компетенший}

Не секрет, что успех учебной деятельности во многом зависит от профессорско-преподавательского состава вуза. Однако даже в условиях полномасштабной глобализации и социальной интеграции далеко не весь педагогический состав владеет навыками иноязычного общения, являясь при этом квалифицированными специалистами в профильных дисциплинах. В связи с этим в последнее время активно ведется работа по обучению преподавателей английскому языку как языку международной коммуникации, что может значительно повысить качество образования, так как учащиеся имеют возмож- 
ность обратиться к преподавателю за дополнительной консультацией по пройденному материалу. Более того, в настоящее время международная сертификация преподавателей по английскому языку является одним из приоритетных факторов при приеме на работу в вузы.

\section{Выводы}

Анализ материалов по изучаемой проблеме, а также обобщение педагогического опыта позволяют сделать следующие выводы:

1. Учитывая возрастающее число программ обучения иностранных студентов, остро встает вопрос о создании специализированных курсов для освоения языка принимающей страны.

2. Требуется адаптация уже имеющихся учебных пособий и создание новых в связи с новыми образовательными тенденциями и возрастающим числом иностранных студентов в вузах России.

3. Использование языка-посредника позволяет проводить сравнительно-сопоставительный анализ лекционных материалов с адаптированными для них печатными изданиями по профильным дисциплинам что, в свою очередь, помогает в более успешном освоении учебного материала. Кроме того, студенты получат возможность принимать участие в коллективной работе и совместных мероприятиях общего профиля.

4. Хорошее владение английским языком становится необходимым профессиональным навыком для преподавателей-предметников. Знание английского языка помогает преподавателю грамотно организовать процесс обучения, а студентам влиться в социум.

Более детальное изучение рассматриваемых методических вопросов и путей их решения является предме- том дальнейших исследований.

\section{Зак^ючение}

Подводя итоги сказанному выше, в первую очередь стоит отметить крайнюю актуальность данной тематики во многих высших учебных заведениях, обучающих иностранных студентов. Нерешенные проблемы социально-психологической адаптации и их периодическое обострение это подтверждают. В свою очередь, акцентирование внимания на трудностях, с которыми приходится сталкиваться иностранным студентам, станет основой для корректировки программы обучения в вузах, способствующей адаптации студентов-иностранцев в потенциально новых условиях.

На сегодняшний день Россия является участником глобального рынка образования. Российское высшее образование имеет ряд конкурентных преимуществ, включая качество и фундаментальность высшего образования, опыт обучения иностранных студентов и относительно невысокую стоимость образовательных услуг. Однако, существуют факторы, препятствующие их экспорту, в связи с чем необходимо обратить внимание на повышение уровня языковой подготовки иностранных студентов и на особенности их адаптации. Изучение этих факторов позволяет определить влияние постоянно меняющихся внешних условий под воздействием глобализации на адаптацию студентов к образовательному процессу в потенциально новой для них среде, а полученные данные помогут осознанно и целенаправленно проектировать, и выстаивать социально-воспитательную и языковую среду университета в будущем. Необходимо строить процесс обучения с учётом индивидуальных способов усвоения званий, индивидуальных темпов учебно-познавательной деятельности каждого ученика и национальных особенностей.

\section{ЛИТЕРАТУРА}

1. Арошидзе М.В. Филология в условиях всеобщий глобализации знаний (исследование проводится в рамках проекта KEAC-BSR №734645 - «Горизонт 2020») // CCS\&ES. 2018. №3. URL: https://cyberleninka.ru/article/n/filologiya-v-usloviyah-vseobschey-globalizatsii-znaniy-issledovanie-provoditsya-v-ramkahproekta-keac-bsr-734645-gorizont-2020 (дата обращения: 14.04.2021)

2. Беккер И.Л., Иванчин С.А. Проблемы адаптации иностранных студентов к образовательному процессу российского вуза (на примере Пензенского государственного университета) // Известия ВУЗов. Поволжский регион. Гуманитарные науки. 2015. №4 (36). URL: https://cyberleninka.ru/article/n/problemyadaptatsii-inostrannyh-studentov-k-obrazovatelnomu-protsessu-rossiyskogo-vuza-na-primere-penzenskogo-gosudarstvennogo (дата 0бращения: 11.04.2021)

3. Капезина Т.Т. Проблемы обучения иностранных студентов в российском вузе // Наука. Общество. Государство. 2014. №1. URL: https://cyberleninka.ru/ article/n/problemy-obucheniya-inostrannyh-studentov-v-rossiyskom-vuze (дата обращения: 21.04.2021)

4. Краснова Г.А. Рекрутинг иностранных студентов в российские вузы [Текст] // Аккредитация в образовании. - 2014. - №1 (69): Февраль. - С. $92-93$

5. Куликова 0.В. Особенности мотивации учения иностранных студентов // Актуальные проблемы гуманитарных и естественных наук. - 2009. - №8. C. $229-232$

6. Налчаджян А.А. Социально-психическая адаптация личности. Ереван, 1988. URL: http://netref.ru/a-a-nalchadjyan-socialeno-psihicheskaya-adaptaciyalichnosti-f.html (дата обращения 21.04.2021)

7. Некипелова И.М. Глобализация языка: неизбежность или необходимость? // Russian Journal of Education and Psychology. 2015. №3 (47). URL: https://cyberleninka.ru/article/n/globalizatsiya-yazyka-neizbezhnost-ili-neobhodimost (дата обращения: 17.04.2021) 
8. Розум С. И. Психология социализации и социальной адаптации человека. СПб.: Речь, 2007. 365 с.

9. Сергеева Л.В. Социально-психологические проблемы адаптации иностранных студентов в межкультурной образовательной среде // Вестник ТГПу. 2017. №5 (182). URL: https://cyberleninka.ru/article/n/sotsialno-psihologicheskie-problemy-adaptatsii-inostrannyh-studentov-v-mezhkulturnoy-obrazovatelnoy-srede (дата обращения: 10.04.2021)

10. Силина Е.В. Феномен глобализации: социальный аспект // Век глобализации: исследования современных глобальных процессов [Текст]/ научно-теоретический журнал. - М.: Издательство «Учитель», 2012г. №2. - С.89

11. Филология и языковая глобализация. — Текст: электронный // Myfilology.ru - информационный филологический ресурс: [сайт]. URL: https://myfilology.ru//154/filologiya-i-yazykovaya-globalizacziya-269/ (дата обращения: 18.04.2021)

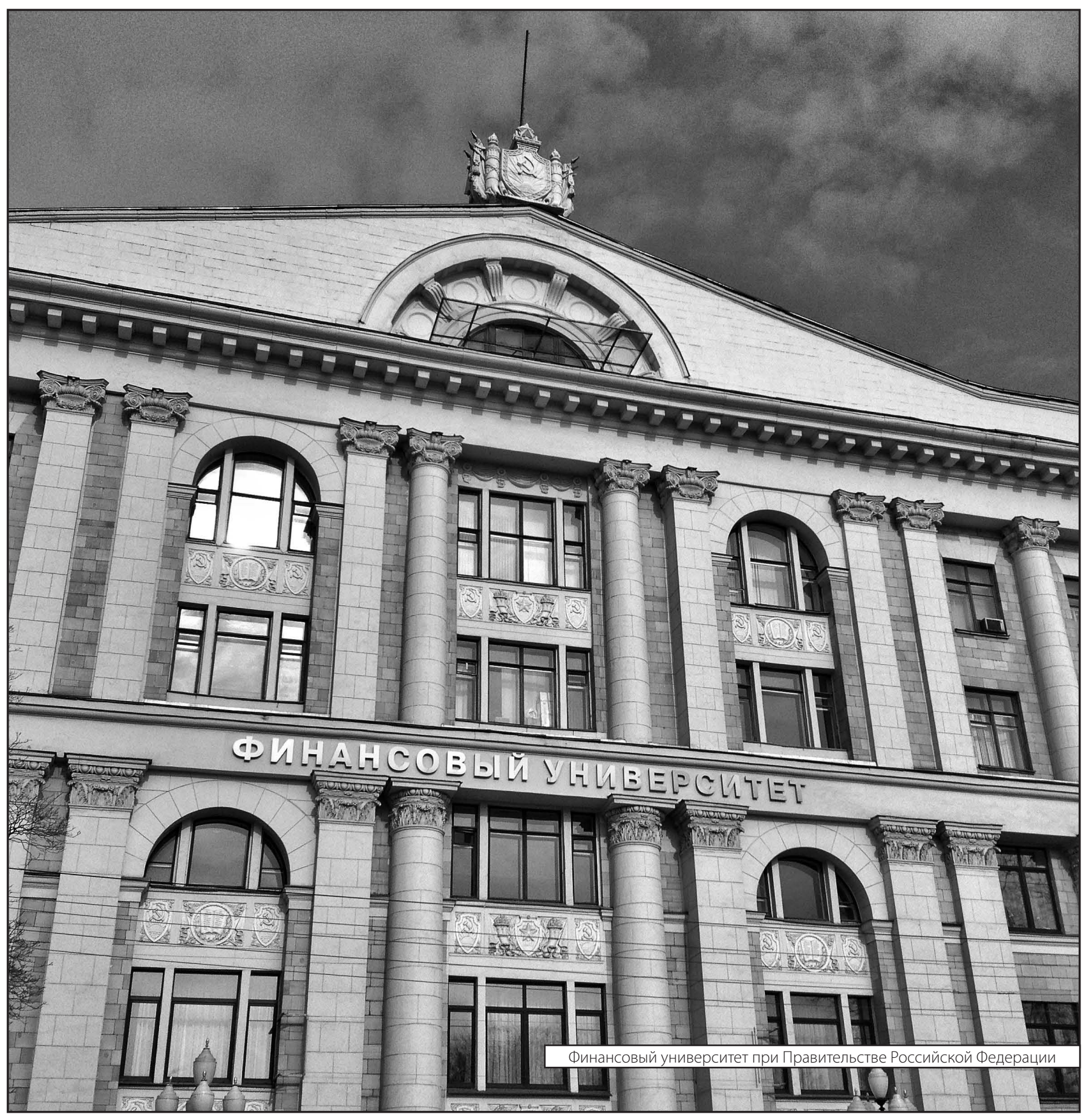

